\title{
Rapid-Sequence Intubation in the Left-Lateral Tilt Position in a Pregnant Woman with Premature Placental Abruption Utilizing a Videolaryngoscope
}

\author{
Kenta Nakao, MD ${ }^{1}$ Nobuyasu Komasawa, MD, $\mathrm{PhD}^{1} \quad$ Yusuke Kusaka, MD, PhD ${ }^{1}$ \\ Toshiaki Minami, MD, PhD ${ }^{1}$ \\ ${ }^{1}$ Department of Anesthesiology, Osaka Medical College, Takatsuki, \\ Osaka, Japan \\ Am J Perinatol Rep 2015;5:e30-e32.

\begin{abstract}
Address for correspondence Nobuyasu Komasawa, MD, PhD, Department of Anesthesiology, Osaka Medical College, Daigakumachi 2-7, Takatsuki, Osaka 569-8686, Japan
\end{abstract} \\ (e-mail: ane078@poh.osaka-med.ac.jp).
}

\author{
Abstract \\ Keywords \\ - rapid-sequence \\ intubation \\ - videolaryngoscope \\ - left-lateral tilt position \\ - premature placental \\ abruption
}

Case A 24-year-old pregnant woman was admitted to our hospital with decreased fetal heart rate. Obstetric examination revealed premature placental abruption; emergent caesarean section was planned under general anesthesia. On entering the operating room, the patient showed severe vital sign deterioration (blood pressure, 75/45 mm $\mathrm{Hg}$; heart rate, 142 beats per minute). As left uterine displacement may worsen the premature placental abruption, the patient was placed in the left-lateral tilt position by rotating the operating table to release compression on the inferior vena cava by theuterus. To avoid circulatory collapse, rapid-sequence intubation was performed in this position. Tracheal intubation was performed with the Pentax-AWS Airwayscope (AWS videolaryngoscope, AWS; HOYA, Japan) to obtain a good laryngeal view and minimize stress from laryngoscopy. After sufficient oxygenation, $120 \mathrm{mg}$ of thiopental was administered. A second anesthesiologist performed cricoid pressure and $50 \mathrm{mg}$ of rocuronium was administered after confirming loss of consciousness. This was followed by insertion of the AWS with a thin intlock into the mouth. Tracheal intubation was performed uneventfully.

Discussion Rapid-sequence intubation in the left-lateral tilted position with the AWS videolaryngoscope may be beneficial for pregnant women with vital sign deterioration.

Premature placental abruption is a serious condition in which the placenta partially or completely separates from the uterus before delivery. This condition can deprive the fetus of oxygen and nutrients, and cause severe bleeding leading to vital sign collapse, which can be dangerous to both the mother and fetus. In cases of premature placental abruption, termination of pregnancy by caesarean section is the standard procedure for rescuing both lives. ${ }^{1}$

Challenges encountered during emergent induction of general anesthesia in pregnant women include vomiting

received

September 27, 2014 accepted after revision November 28, 2014 published online February 25, 2015 and difficult airways. ${ }^{2}$ Also challenging are cases of shock due to disseminated intravascular coagulation. Here, we report the successful rapid-sequence intubation of a pregnant woman using a videolaryngoscope in the left-lateral tilt position.

\section{Case Report}

A 24-year-old pregnant woman (height, $152 \mathrm{~cm}$; weight, $55 \mathrm{~kg}$ ) was admitted to our hospital with decreased fetal

Copyright $\odot 2015$ by Thieme Medical Publishers, Inc., 333 Seventh Avenue, New York, NY 10001, USA. Tel: +1(212) 584-4662.
License terms

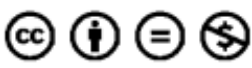

$10.1055 / \mathrm{s}-0034-1544109$ ISSN 2157-6998. 
heart rate. Obstetric examination revealed premature placental abruption; emergent caesarean section was planned under general anesthesia.

On entering the operating room, the patient showed severe vital sign deterioration (blood pressure, 75/45 mm Hg; heart rate, 142 beats per minute). We considered the possibility that manual left uterine displacement may worsen premature placental abruption, leading to further vital sign deterioration. The patient was placed in the left-lateral tilt position by rotating the operating table to release compression on the inferior vena cava by the uterus. ${ }^{3}$ Medical staff stood on the left and helped prevent the patient from falling off the table. To avoid circulatory collapse, rapid-sequence intubation was performed in this position. Tracheal intubation was performed with the Pentax-AWS Airwayscope (AWS; HOYA, Japan) to obtain a good laryngeal view and minimize stress from laryngoscopy. After sufficient oxygenation, $120 \mathrm{mg}$ of thiopental was administered. A second anesthesiologist performed cricoid pressure and $50 \mathrm{mg}$ of rocuronium was administered after confirming loss of consciousness. This was followed by insertion of the AWS with a thin intlock into the mouth. Tracheal intubation with a tube (internal diameter, $7.0 \mathrm{~mm}$ ) was performed uneventfully. After tracheal intubation, nitrous oxide and sevoflurane were administered. The infant was surgically delivered and vital signs recovered gradually with colloid infusion. Postoperative analgesia was performed with intravenous fentanyl and transversus abdominis plane block with ropivacaine. She was extubated in the operating room uneventfully. The Apgar score of the infant was 4 at 1 minute, and 9 at 5 minutes. The infant and mother were discharged with no major complications on postoperative day 7 .

\section{Discussion}

Airway management with general anesthesia, even for elective caesarean section, is potentially difficult because patients have a low tolerance to hypoxia, high risk of aspiration from a rise in gastric pressure, and unique upper airway narrowing. ${ }^{2,4}$ The incidence of failed tracheal intubation is much higher in pregnant patients than in nonpregnant patients. In emergent situations, the difficulty increases. The American Heart Association 2010 cardiopulmonary resuscitation guidelines recommend early and careful securing of the airway during emergencies in pregnant women. ${ }^{5}$

The conventional Macintosh laryngoscope is the most widely used laryngoscope for tracheal intubation in obstetrics airway management, but its use requires skill and the incidence of inaccurate intubation can be unacceptably high, especially for occasional operators. Failure of tracheal intubation during cardiopulmonary resuscitation can result in serious complications such as stomach expansion, vomiting, and hypoxia, leading to poor outcomes. ${ }^{2,4}$

The AWS is a videolaryngoscope for tracheal intubation designed to provide a clear view of the glottis and its surrounding anatomy. 6,7 The AWS improves the laryngeal view and its tube guide facilitates rapid and accurate tracheal intubation, even for difficult cases such as cervical neck immobility and morbid obesity. ${ }^{6,8}$ Increasing evidence indi- cates that the AWS is suitable for tracheal intubation during emergent situations, such as cardiopulmonary resuscitation or various position..$^{9-11}$ Furthermore, the AWS requires less operator skill and is well suited for operators who perform infrequent tracheal intubations. ${ }^{12}$ Several simulation and clinical reports have attested to the utility of the AWS for rapid and definite tracheal intubation during obstetric emergencies. ${ }^{13,14}$ One simulation study showed the utility of AWS during continuous chest compression in the left-lateral tilt. ${ }^{13}$ Kariya et al demonstrated the utility of awake intubation during Cesarean section. ${ }^{14}$

There were three major advantages to using the AWS in this case. First, the AWS allowed for a good laryngeal view via the indirect glottis view function, although laryngoscopy was anticipated to be difficult due to late pregnancy. ${ }^{15}$ Second, rapid-sequence tracheal intubation was performed uneventfully in the left-lateral tilt position with the AWS, which has been successfully used in various positions. ${ }^{9,14}$ Third, stress from laryngoscopy was minimized by using the AWS, which allowed for the use of a relatively small amount of thiopental to avoid vital sign collapse. ${ }^{16}$

Our findings suggest that rapid-sequence intubation in the left-lateral tilted position with the AWS videolaryngoscope may be beneficial for emergent airway management of pregnant women.

\section{Patient Consent}

A written consent was obtained from the patient for publishing this report.

\section{Conflict of Interest}

The authors have no affiliation with any manufacturer of any device described in the article and declare no financial interest in relation to the material described herein.

\section{Acknowledgment}

Financial support for the study was provided by our institution and department.

\section{References}

1 Tyner JE, Rayburn WF. Emergency cesarean delivery: special precautions. Obstet Gynecol Clin North Am 2013;40(1):37-45

2 McDonnell NJ, Paech MJ, Clavisi OM, Scott KL; ANZCA Trials Group. Difficult and failed intubation in obstetric anaesthesia: an observational study of airway management and complications associated with general anaesthesia for caesarean section. Int J Obstet Anesth 2008;17(4):292-297

3 Bamber JH, Dresner M. Aortocaval compression in pregnancy: the effect of changing the degree and direction of lateral tilt on maternal cardiac output. Anesth Analg 2003;97(1):256-258

4 Djabatey EA, Barclay PM. Difficult and failed intubation in 3430 obstetric general anaesthetics. Anaesthesia 2009;64(11): 1168-1171

5 Vanden Hoek TL, Morrison LJ, Shuster M, et al. Part 12: cardiac arrest in special situations: 2010 American Heart Association 
e32 Rapid-Sequence Intubation for Premature Placental Abruption by a Videolaryngoscope Nakao et al.

Guidelines for Cardiopulmonary Resuscitation and Emergency Cardiovascular Care. Circulation 2010;122(18, Suppl 3): S829-S861

6 Asai T, Liu EH, Matsumoto S, et al. Use of the Pentax-AWS in 293 patients with difficult airways. Anesthesiology 2009;110(4): 898-904

7 Suzuki A, Toyama Y, Katsumi N, et al. The Pentax-AWS((R)) rigid indirect video laryngoscope: clinical assessment of performance in 320 cases. Anaesthesia 2008;63(6):641-647

8 Komasawa N, Ueki R, Nomura H, Itani M, Kaminoh Y. Comparison of tracheal intubation by the Macintosh laryngoscope and PentaxAWS (Airway Scope) during chest compression: a manikin study. J Anesth 2010;24(2):306-308

9 Komasawa N, Ueki R, Itani M, Nomura H, Nishi SI, Kaminoh Y. Evaluation of tracheal intubation in several positions by the Pentax-AWS Airway Scope: a manikin study. J Anesth 2010; 24(6):908-912

10 Asai T. Tracheal intubation with restricted access: a randomised comparison of the Pentax-Airway Scope and Macintosh laryngoscope in a manikin. Anaesthesia 2009;64(10):1114-1117

11 Komasawa N, Ueki R, Itani M, Nishi S, Kaminoh Y. Validation of the Pentax-AWS Airwayscope utility as an intubation device during cardiopulmonary resuscitation on the ground. J Anesth 2010; 24(4):582-586

12 Hirabayashi Y, Seo N. Tracheal intubation by non-anesthesia residents using the Pentax-AWS airway scope and Macintosh laryngoscope. J Clin Anesth 2009;21(4):268-271

13 Kariya N, Kimura K, Iwasaki R, Ueki R, Tatara T, Tashiro C. Intraoperative awake tracheal intubation using the Airway Scope $^{\mathrm{TM}}$ in caesarean section. Anaesth Intensive Care 2013; 41(3):390-392

14 Kohama H, Komasawa N, Ueki R, et al. Utility of the Pentax-AWS Airwayscope and Macintosh laryngoscope for airway management during chest compressions in $27^{\circ}$ left-lateral tilt: a manikin simulation study of maternal cardiopulmonary resuscitation. J Anesth 2013;27(5):671-675

15 Lipman S, Cohen S, Einav S, et al; Society for Obstetric Anesthesia and Perinatology. The Society for Obstetric Anesthesia and Perinatology consensus statement on the management of cardiac arrest in pregnancy. Anesth Analg 2014;118(5):1003-1016

16 Nishikawa K, Matsuoka H, Saito S. Tracheal intubation with the PENTAX-AWS (airway scope) reduces changes of hemodynamic responses and bispectral index scores compared with the Macintosh laryngoscope. J Neurosurg Anesthesiol 2009;21(4):292-296 